\title{
Randomized clinical trial comparing the effect of paracetamol with diclofenac in combination with on request rescue analgesic tramadol: analgesic efficacy, safety and tolerability after abdominal surgery
}

\author{
Prashant Hombal $^{1 *}$, Anupama M. Gudadappanavar ${ }^{2}$, Avinash Kavi ${ }^{3}$
}

${ }^{1}$ Department Of General Surgery, ${ }^{2}$ Department Of Pharmacology, ${ }^{3}$ Department Of Community Medicine, J. N.
Medical College, KLE University, Belagavi, Karnataka, India

Received: 04 March 2016

Revised: 07 March 2016

Accepted: 09 March 2016

\section{*Correspondence:}

Dr. Prashant R. Hombal,

E-mail: prash1526@rediffmail.com

Copyright: () the author(s), publisher and licensee Medip Academy. This is an open-access article distributed under the terms of the Creative Commons Attribution Non-Commercial License, which permits unrestricted non-commercial use, distribution, and reproduction in any medium, provided the original work is properly cited.

\section{ABSTRACT}

Background: The study was planned to assess the efficacy and safety of paracetamol in comparison with diclofenac for post-operative analgesic pain in patients undergoing elective abdominal surgery. This, randomized clinical trial was conducted in an institution of medical education and tertiary care centre.

Methods: 90 patients scheduled for elective abdominal surgery were assigned in a randomized manner in to two groups. Group P received $1 \mathrm{~g}$ paracetamol intravenously (IV) 8 hourly and group D received 75 mg intramuscular (IM) diclofenac $8^{\text {th }}$ hourly for $24 \mathrm{hr}$ post-operative period. The pain intensity was judged using pain visual analogue score (VAS) at time periods $2 \mathrm{~h}, 4 \mathrm{~h}, 6 \mathrm{~h}, 12 \mathrm{~h}, 18 \mathrm{~h}$ and $24 \mathrm{~h}$ post-surgery. Patient reported with a VAS pain score of greater than 3, a rescue analgesic IV tramadol $100 \mathrm{mg}$ injection was given. The need of rescue analgesic, pain VAS, patient satisfaction score and adverse effects were recorded.

Results: The data was expressed in mean +/-SD and analysed using unpaired t test, chi-square test, followed by Fisher's exact post-hoc test. Total tramadol requirement were not significantly different between paracetamol and diclofenac groups. Gastrointestinal side effects were present in $6.6 \%$ and $17.7 \%$ of patients receiving paracetamol and diclofenac respectively. Patient satisfaction score till administration of rescue analgesics showed statistically significant difference $(\mathrm{p}=0.043)$ between the groups.

Conclusions: Paracetamol is equally effective and safer which can be a practicable alternative compared to Diclofenac especially because of its highly encouraging risk benefit-ratio, which justify its role as a near-routine management for post-operative pain.

Keywords: Diclofenac, Paracetamol, Postoperative pain, Tramadol

\section{INTRODUCTION}

Pain is a most common symptom of any illness. The international association for the study of Pain's widely used definition states: "Pain is an unpleasant sensory and emotional experience associated with actual or potential tissue damage, or described in terms of such damage". Major abdominal surgeries with upper abdominal incision lead to severe postsurgical pain, which if treated inadequately, can cause shallow breathing, atelectasis, and retention of secretions and lack of cooperation during physiotherapy. This increases the incidence of post-operative morbidity and leads to delayed recovery. ${ }^{2}$ Management of acute post-operative pain has been given more importance in recent years with considerable concurrent advancement in this regard. Despite this advancement, post-operative pain continues to be a challenge and often leads to patient dissatisfaction. ${ }^{3,4}$ 
Non-steroidal anti-inflammatory drugs (NSAIDs) have been advocated to provide "multimodal" or "balanced" analgesia that decreases opioid dose requirements and may reduce related adverse events while reducing postoperative pain. Paracetamol (acetaminophen) is one of the most popular and most commonly used analgesic and antipyretic drug around the world, the drug of choice in patients who cannot be treated with NSAIDs, such as bronchial asthma, peptic ulcer disease, hemophilia, and salicylate-sensitization, children under 12 years of age, pregnant or breastfeeding women. ${ }^{5,6}$ It is a poor inhibitor of prostaglandins (PG) synthesis in peripheral tissues, but more active on cyclooxygenase (COX) in the brain. It raises pain threshold and its ability to inhibit COX-3 could also account for its analgesic-antipyretic action. In contrast to other NSAIDs, paracetamol does not stimulate respiration or affect acid-base balance and does not increase cellular metabolism. It has no effect on cardiovascular system (CVS). Gastric irritation is insignificant mucosal erosion and bleeding occurs rarely. It does not affect platelet function or clotting factors and is not uricosuric. 6 ,

Diclofenac is one of the most extensively used NSAID; employed in rheumatoid and osteoarthritis, bursitis, ankylosing spondylitis, toothache, dysmenorrhoea, renal colic, posttraumatic and postoperative inflammatory conditions. The mechanism of action of diclofenac goes beyond COX inhibition and include inhibition of thromboxane-prostanoid receptor, affecting arachidonic acid release and uptake, inhibition of lipoxygenase enzymes and activation of the nitric oxide-cyclic guanosine monophosphate anti-nociceptive pathway., ${ }^{6,8}$ But it has shown to increase the risk of heart attack, stroke and reversible elevation of serum aminotransferases apart from its regular gastrointestinal (GI) side effects like epigastric pain, nausea and even headache, dizziness, rashes, etc. ${ }^{6,7}$

Post-operative pain control is an issue dealt with in recent years. Sincere efforts are of utmost importance as effective pain relief is a main objective to modify surgical stress responses, thereby leading to an improved outcome. ${ }^{4,5}$ The opioid sparing effect of NSAIDs has often been used as an analgesic efficacy parameter. Several research and review studies have concluded that the combination of paracetamol with widely used NSAIDs proved to be synergistic and provide superior analgesia than either drug alone. ${ }^{4,9,10}$ But the research work on paracetamol as single analgesic agent for postoperative pain are very minimal and they have got only selected outcomes. Intravenous paracetamol is a newer concept gaining global popularity in acute postoperative pain relief. We consider that the comparison of paracetamol with diclofenac in post-operative pain management is important especially as the side effects of these compounds are so different.

Hence, study included other important factors like efficacy, safety and duration of action of paracetamol for the evaluation of postoperative pain in comparison to diclofenac. With these objectives we planned a comparative study of two analgesic drugs paracetamol (IV) and diclofenac (IM).

\section{METHODS}

This is a randomized clinical trial conducted in an Institution of Medical Education and Tertiary Care Centre in Karnataka, India. The study was approved by Institutional Ethics Committee for Humans and trial is registered under Clinical Trial Registry India (CTRI; $\mathrm{REF} / 2015 / 05 / 009014)$. The sample size is calculated on the assumption of a standard deviation (SD) 0.58 of the expected difference from previous studies ${ }^{3,5}$ with a power of $>80 \%$ to detect this difference. The calculated sample size came out as 90 and hence patients were equally assigned in each of group P and group D. The informed consent from all study participants was obtained and the baseline characteristics like age, sex and body mass index (BMI) were noted for comparison. Every patient was individually randomized by envelope method hence had equal opportunity to be in either of the groups.

The patients undergoing elective abdominal surgery between the age group of 18 to 50 years and in the physiological group of American Society of Anaesthesiologist (ASA) I \& II physical status with no major systemic disease were included in the study. The patients with history of drug allergy to any of the study drug, chronic alcoholism or daily intake of NSAIDS for long time were excluded from the study.

Group D patients received $75 \mathrm{mg} / 3 \mathrm{ml}$ diclofenac IM in gluteal region and Group $\mathrm{P}$ patients received $1 \mathrm{~g} / 100 \mathrm{ml}$ paracetamol IV (100 $\mathrm{ml}$ saline in $15 \mathrm{mins}) 8^{\text {th }}$ hourly for 24 hrs post-operative period from the end of surgery. The patients were observed for $24 \mathrm{hrs}$ after surgery. The pain intensity was judged using a 10 point visual analog score (VAS) scale at time periods 2, 4, 6, 12, 18 and $24 \mathrm{hrs}$ after the surgery. Safety and tolerability were evaluated by the occurrence of adverse events, especially the incidence and severity of gastrointestinal symptoms. If a patient reported a VAS pain score of greater than 3 , a rescue analgesic in the form of IV tramadol $100 \mathrm{mg}$ injection was given. The need of rescue analgesic was recorded for both the groups at time periods $2,4,6,12$, 18 and $24 \mathrm{~h}$ after surgery. ${ }^{2,4}$

The primary outcome of our study was VAS until first rescue analgesic request and the requirement of rescue analgesic in the form of injection tramadol over $24 \mathrm{hrs}$. The secondary outcomes measured was patient satisfaction score (PSC) till rescue analgesic was given and adverse events. VAS was measured on a scale from 0 to 10 and rescue analgesic was administered at any score greater than 3. PSC was assessed using a four point rating scale $(\text { poor }=0, \text { fair }=1 \text {, good }=2 \text { and excellent }=3)^{2-4,11}$ 


\section{Statistical analysis}

Statistical analysis was performed using SPSS 17.0 for windows 7 version. Data were expressed as mean values and standard deviation (mean \pm SD). Data was analyzed using unpaired $t$ test, chi-square test, followed by Fisher's exact test. $\mathrm{P}<0.05$ was considered as statistically significant.

\section{RESULTS}

Participants were enrolled and analyzed as shown in Figure 1. (Consort flow diagram). Ninety patients were identified by the surgeon and consented for the study. There were 27 men and 18 females in group P and 35 men and 10 females in group D. Both the allocated groups were compared on a number of variables like baseline characteristics, duration of surgery, total tramadol requirement and number of patients requiring rescue analgesics to ensure adequate randomization; the comparisons are shown in Table 1 and did not differ significantly.
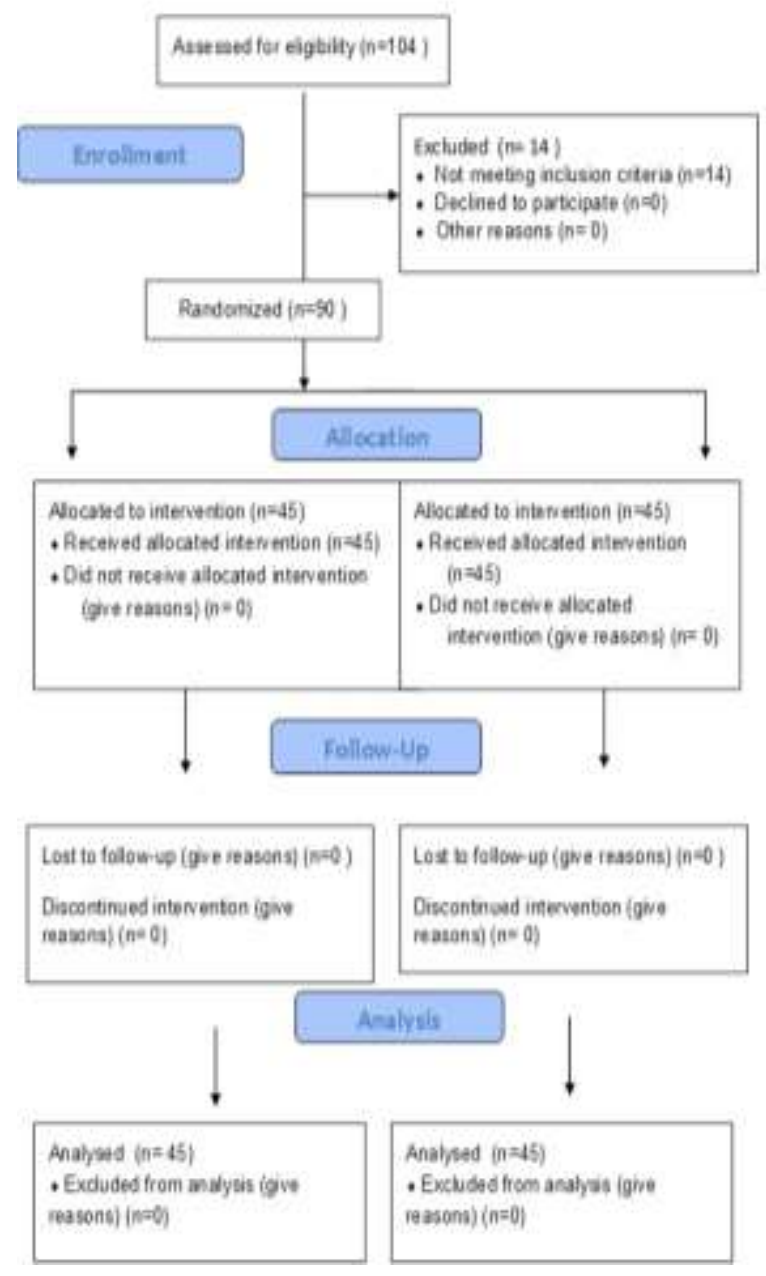

Figure 1: Consort flow diagram of study.
Table 1: Demographic and baseline characteristics (results are in Mean \pm SD).

\begin{tabular}{|lll|}
\hline & $\begin{array}{l}\text { Group P } \\
(\mathbf{n}=\mathbf{4 5})\end{array}$ & $\begin{array}{l}\text { Group D } \\
(\mathbf{n = 4 5})\end{array}$ \\
\hline Age $(\mathrm{yrs})$ & $39.44 \pm 15.11$ & $39.96 \pm 17.68$ \\
\hline BMI $\left(\mathrm{kg} / \mathrm{m}^{2}\right)$ & $21.73 \pm 1.85$ & $20.93 \pm 2.38$ \\
\hline ASA (I/II) & $1.37 \pm 0.49$ & $1.40 \pm 0.49$ \\
\hline $\begin{array}{l}\text { Duration of surgery } \\
\text { (mins) }\end{array}$ & $70.78 \pm 17.74$ & $77.53 \pm 21.31$ \\
\hline $\begin{array}{l}\text { Total tramadol } \\
\text { requirement (mg) }\end{array}$ & $600 \mathrm{mg}$ & $400 \mathrm{mg}$ \\
\hline $\begin{array}{l}\text { No. of patients } \\
\text { requiring rescue } \\
\text { analgesic (n) }\end{array}$ & $05(11.1 \%)$ & $04(8.8 \%)$ \\
\hline
\end{tabular}

The data were expressed in the form of mean \pm SD. Pain intensity in the form of post-operative pain VAS score were shown in Table 2. VAS score was zero on 2 nd hour post operatively and the mean of VAS score recorded at $4^{\text {th }}, 6^{\text {th }}, 12^{\text {th }}, 18^{\text {th }}$ and $24^{\text {th }}$ hr showed no significant difference between the two groups ( $p$ value $>0.05$ ). The same was tabulated and shown in the Figure 2. Tramadol requirement during $24 \mathrm{hr}$ was $600 \mathrm{mg}$ in group $\mathrm{P}$ and 400 $\mathrm{mg}$ in group D. There was no clinical or statistical difference between both groups of patients requiring rescue analgesic.

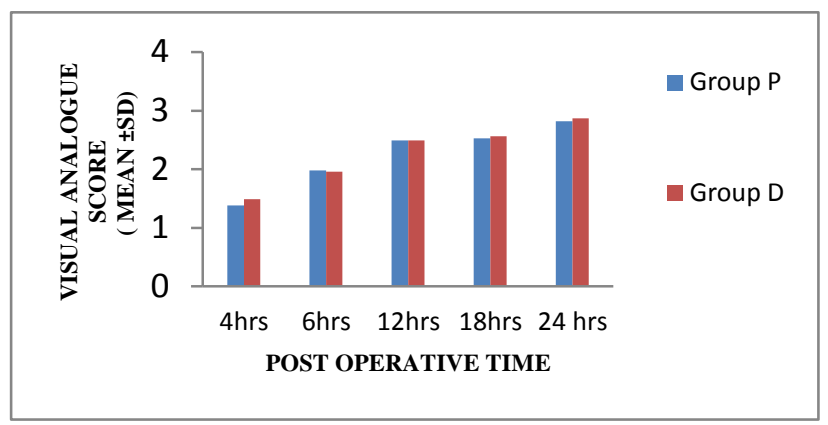

Figure 2: Visual analogue score.

Patient satisfaction score (PSC) till administration of rescue analgesic were represented in Table 2 and Figure 3 , which depicts there is statistically significant difference between the groups $\left({ }^{*} \mathrm{p}=0.043\right)$. Good PSC score is appreciably more with group $\mathrm{P}$ when compared to group D. Patient satisfaction is an important indicator of quality of care because of its relevance to compliance and better patient outcome. Side effects occurred in small fraction i.e. nausea occurred in $8.8 \%$ of the participants in group D and $4.4 \%$ among group P. Vomiting occurred among $17.8 \%$ of group D participants $(\mathrm{p}=0.108)$ and $6.7 \%$ among group $P$ participants $(p=0.398)$ respectively and were not statistically significant. In general, no clinically significant changes in vital signs or laboratory values or no major adverse drug reactions to the drugs were noted in our study. 
Table 2: VAS and PSC at 4, 6, 12, 18 and 24 hour post-operatively.

\begin{tabular}{|c|c|c|c|}
\hline & Group P & Group D & P value \\
\hline \multicolumn{4}{|c|}{ Visual analogue scale [mean $( \pm$ SD $)]$} \\
\hline VAS at $4 \mathrm{hrs}$ & $1.38 \pm 0.53$ & $1.49 \pm 0.63$ & 0.116 \\
\hline VAS at $6 \mathrm{hrs}$ & $1.98 \pm 0.62$ & $1.96 \pm 0.60$ & 0.737 \\
\hline VAS at $12 \mathrm{hrs}$ & $2.49 \pm 1.14$ & $2.49 \pm 1.29$ & 0.812 \\
\hline VAS at $18 \mathrm{hrs}$ & $2.53 \pm 0.59$ & $2.56 \pm 0.58$ & 0.963 \\
\hline VAS at $24 \mathrm{hrs}$ & $2.82 \pm 0.75$ & $2.87 \pm 0.58$ & 0.226 \\
\hline \multicolumn{4}{|c|}{ Patient satisfaction score [n (\%)] } \\
\hline Poor & $01(2.2)$ & $0(0)$ & \multirow{4}{*}{$\begin{array}{l}\text { Fisher's } \\
\text { Exact } \\
\text { Test }= \\
5.592 \\
\text { df }=2 \\
\mathrm{P}=0.043^{*} \\
\text { (Signific } \\
\text { ant) }\end{array}$} \\
\hline Fair & $10(22.2)$ & $20(44.4)$ & \\
\hline Good & $34(75.6)$ & $25(55.6)$ & \\
\hline Excellent & $0(0)$ & $0(0)$ & \\
\hline
\end{tabular}

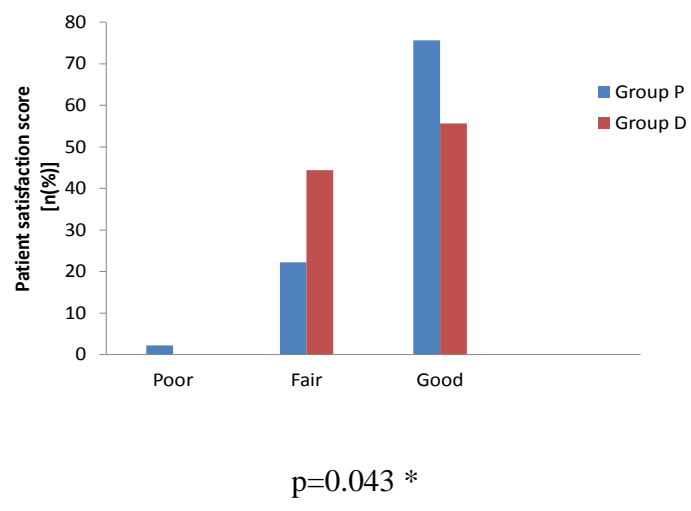

Figure 3: Patient satisfaction score.

\section{DISCUSSION}

All surgical procedures will produce pain of variable intensity. Post-operative pain of severe intensity is implicated in respiratory excursion, atelectasis and also prolong gastroileus, urinary retention, increased risk of deep vein thrombosis. ${ }^{12}$ It is also well known that the increased level of catecholamine due to surgery will in turn increase in myocardial work and oxygen consumption. The introduction of NSAIDs has decreased the use of narcotics and is useful in patients who are tolerant to opiates and in elder patients. Narcotic analgesics have limitations like respiratory depression or narcotic addiction, so most of clinicians do not prefer to prescribe them. ${ }^{1,12,13}$

In our study, the statistical results across the study groups showed that the primary outcome measure i.e. pain VAS score and the requirement of rescue analgesics did not show clinically or statistically significant difference between paracetamol and diclofenac groups. But both showed an opioid sparing effect approximately up to $90 \%$ $(91.2 \%$ and $88.9 \%$ respectively in paracetamol and diclofenac groups) in patient controlled analgesia. It's known that paracetamol gives more reliable therapeutic plasma concentrations when given intravenously and paracetamol can be a practicable alternative to diclofenac especially because of low incidence of adverse effects, better compliance and can be a preferred choice in high risk patients.

There are multiple measures available to assess pain in adult patients. Pain VAS is a unidimensional single item known for its simplicity and adaptability that provide an estimate of pain intensity in patients both in terms of quantity and quality. ${ }^{11}$ The pain VAS has found to be more reliable and accepted by our patients and showed sensitivity to changes in pain assessed hourly during research.

Even if the number of adverse events were low in both treatment groups, there is a trend toward a reduction in GI symptoms with paracetamol, as suggested by a reduced incidence of gastrointestinal side effects $(6.6 \%$ of patients compared with $17.7 \%$ in the diclofenac group) that did not reach statistical significance. The reported adverse effects like nausea and vomiting were more with diclofenac group. During interpretation of our findings related to side effects, we were very careful in differentiating these side effects from that of residual effects of anesthesia and surgery. Other less expected side effects mentioned in earlier studies like allergy, hypotension, hepatotoxicity, altered blood count, etc were not found in any patients enrolled in this study.

Pal et al. in their study of 102 patients undergoing lower abdominal gynaecological surgery compared paracetamol (1 gm/100ml) IV, diclofenac $(75 \mathrm{mg} / 3 \mathrm{ml})$ IM and combination of both. They found that the diclofenac and its combination with paracetamol showed better efficacy when compared to paracetamol alone in terms of the requirement of rescue analgesics. ${ }^{5}$ Nath et al, studied the effect of IV paracetamol in comparison to IV tramadol for patients undergoing lower abdominal surgery and found that the iv paracetamol can be better alternative to tramadol in terms of efficacy and safety. ${ }^{3}$ Two different studies done on patients undergoing elective gynaecological surgeries compared paracetamol, diclofenac and their combination; gives two different results, one showing combination is better with $40 \%$ decrease in pain intensity, another showed no significant difference in pain intensity among groups. ${ }^{14,15}$ Very few studies state that the analgesic efficacy of intravenous paracetamol was comparable and superior to that of tramadol or diclofenac which are standard postoperative analgesics used for abdominal surgery.

Study limitations were that blinding was not possible because of different routes of drug administration and it may need large sample size to generalize the results. 


\section{CONCLUSION}

In conclusion, this randomized clinical trial shows that IV paracetamol is equally effective and safer which can be a practicable alternative compared to IM diclofenac especially because of its highly encouraging risk benefitratio, which might justify its role as a near -routine management for post-operative pain. There is still need of lot of research work with large sample size for further evaluation of paracetamol and its place in postoperative pain management. We believe that this study provide new facts in relation to benefit patients and assist concerned clinician to prepare post-operative pain management guidelines while selecting analgesics.

\section{ACKNOWLEDGEMENTS}

The author would like to thank Dr. Netravati Angadi MD and Mr. M. D. Mallapur for their support in the study. The authors specially acknowledge with thanks to all the staff of department of general surgery, KLE's Dr. Prabhakar Kore Charitable Hospital, Belagavi.

Funding: No funding sources

Conflict of interest: None declared

Ethical approval: The study was approved by the institutional ethics committee

\section{REFERENCES}

1. IASP Sub-committee on taxonomy. Pain terms: a list with definitions and notes on usage. Pain. 1980;8:249-52.

2. Alistare P, Nicholas CM, Armitage. Postoperative care. Bailey and love's short practice of surgery. 25th ed. London: Edward Arnold Ltd;2008:258-268.

3. Nath R, Dutta S, Medom K, Khandelwal A. Evaluation of the analgesic efficacy and safety of intravenous paracetamol in comparison to intravenous tramadol for post-operative analgesia in patients undergoing lower abdominal surgery. J Evol Med And Dent Sci. 2015;4(4):505-13.

4. Ahmed A, Latif N, Khan R. Post-operative analgesia for major abdominal surgery and its effectiveness in a tertiary care hospital. Anaesthesiol Clin Pharmacol. 2013;29(4):472-7.
5. Pal A, Biswas J, Mukhopadhyay P, Sanyal P, Dasgupta S, Das S. Diclofenac is more effective for post-operative analgesia in patients undergoing lower abdominal gynecological surgeries: A comparative study. Anesth Essays Res. 2014;8(2):192-6.

6. Jóźwiak-Bębenista M, Nowak JZ. Paracetamol: mechanism of action, applications and safety concern. Acta Poloniae Pharmaceutica N Drug Research. 2014;71:11-23.

7. Tripati KD. Essential of Medical Pharmacology $7^{\text {th }}$ ed. New Delhi (India): Jaypee Brothers Medical Publishers; 2014.

8. Brunton LL, Laso JS, Parker KL. Goodman Gilman A. The pharmacological basis of therapeutics. $11^{\text {th }}$ ed. New York: McGraw Hill; 2001.

9. Gan TJ. Diclofenac: an update on its mechanism of action and safety profile. Curr Med Res Opin. 2010;26:1715-31.

10. Miranda HF, Puig MM, Prieto JC, Pinardi G. Synergism between paracetamol and nonsteroidal anti-inflammatory drugs in experimental acute pain. Pain. 2006;121:22-8.

11. Ong CKS, Seymour RA, Lirk P, Merry AF. Combining paracetamol (acetaminophen) with nonsteroidal anti-inflammatory drugs: A qualitative systematic review of analgesic efficacy for acute postoperative pain. Intern Anaesth Res Soc. 2010;110:1170-9.

12. Hawker GA, Mian S, Kendzerska T, French M. Measures of adult pain. Arthr Care Res. 2011;63(11):240-52.

13. Liu CD, Macfadden DW. Maingots abdominal operations $10^{\text {th }}$ ed; Appleton \& Lange Stamford; York production services:1997.

14. Munishankar, Fettes P, Moore C, McLeod GA. A double-blind randomized controlled trial of paracetamol, diclofenac or the combination for pain relief after caesarean section. Int J Obstet Anesth 2008;17:9-14.

15. Montgomery JE, Sutherland CJ, Kestin IG, Sneyd JR. Morphine consumption in patients receiving rectal paracetamol and diclofenac alone or in combination. Br J Anaesth. 1996;77:445-7.

Cite this article as: Hombal P, Gudadappanavar AM, Kavi A. Randomized clinical trial comparing the effect of paracetamol with diclofenac in combination with on request rescue analgesic tramadol: analgesic efficacy, safety and tolerability after abdominal surgery. Int Surg J 2016;3:557-61. 